\title{
Study of the effect of the introduction of the back yarn on two-layer knitted fabric's physical and mechanical properties
}

\author{
Sadoqat Rahmatova ${ }^{1 *}$, Nozimjon Jurabayev ${ }^{1}$, and Qurbonali Holikov ${ }^{1}$ \\ ${ }^{1}$ Namangan Institute of Engineering and Technology, 160115 Namangan, Uzbekistan
}

\begin{abstract}
In this research work, the physical and mechanical properties of 3 variants of jacquard knitted fabric obtained in order to increase the heat retention properties and increase the range of knitted fabrics by adding back yarn to the base of glad, rubber cuts in 20 grade double-needle jacquard knitting machine using local raw materials effectively The technological indicators were obtained experimentally and tabulated and recommendations for production sectors are given.
\end{abstract}

\section{Introduction}

By incorporating patterned knitted fabric elements into the structure of the knitted fabric, it is possible to reduce the consumption of raw materials along with the effect of the pattern effect on the physical and mechanical performance of the obtained fabrics, and thus economic efficiency is achieved [1]. Expansion of the range of knitted products produced through the efficient use of local raw materials and the study of its impact on the physicomechanical and technological performance as a result of the introduction of back yarn in two-layer knitted fabric was determined experimentally in the testing laboratory of NamMTI textile and knitted products [2]. Glad produced 3 variants of knitted fabric, which included a back strip, based on the attachment of two-layer knitted fabric on the basis of rubber fabric by the method of pattern [3].

The inclusion of a back strip in the fabric meets the operational requirements for the fabric's elongation, shape retention, heat retention, deformation properties and the range of products recommended [4].

It is called a knitted backing fabric that contains additional yarns that are not woven together with the hoop. These additional threads are located between the loop bases or protrusions and are called back threads [5]. The inclusion of a backing strip in the fabric structure leads to a sharp decrease in machine productivity. But the knitwear effectively serves the purpose of expanding the range of knitted products, this yarn, which is used as a backing yarn, does not reduce the elongation of the knit width, but at the same time increases the elasticity property [6]. Nowadays, it is possible to produce glad, tire-based backing knitted fabric without removing the glad rings [7].

\footnotetext{
*Corresponding author: sadoqat.ziynat@gmail.com
} 
In this article, a polyester yarn with a linear density of 100 tex, a 20-tex cotton yarn on both sides of the knitted fabric was used as the back yarn in the two-circle needle jacquard knitting machine, and its physical-mechanical and technological parameters were tested in NamMTI textile-knitted products. experimented in the laboratory.

Analysis of the composition of raw material consumption standards in the production of outerwear and domestic knitwear, normative indicators of GOST and TS, allows to identify two main directions of reducing the consumption of raw materials per unit of knitted goods $[8,9]$ :

- reduction of raw material consumption per unit of fabric;

- reduction of production waste on all technological processes.

In order to reduce the consumption of raw materials per unit of output, it is necessary to ensure the development of knitted fabrics with many economical new structure, the use of resource-saving and waste-free technologies.

Raw material consumption is an indicator of the mass consumption of textile yarns per unit of product or per square meter of knitted fabric. According to GOST 8845-87, the consumption of raw materials for knitted fabrics is characterized by the indicator "surface density" MS and its unit of measurement is $\mathrm{g} / \mathrm{m}^{2}[10]$.

\section{Materials and Methods}

Samples of backed two-layer knitted fabric were produced on OVJA 1,6ER type 20 class two-circle needle jacquard knitting machines [11]. Currently, there is great interest in the production of knitted fabrics produced by circular double-needle jacquard machines, which are widely used in domestic enterprises for the production of top knitwear [12].

Table 1. Physico-mechanical properties of backed two-layer knitted fabric

\begin{tabular}{|c|c|c|c|c|}
\hline \multirow{2}{*}{\multicolumn{2}{|c|}{ Indicators }} & \multicolumn{3}{|c|}{ Variants } \\
\hline & & \multirow{2}{*}{$\begin{array}{c}\text { I } \\
\text { Cotton thread } \\
20 \text { tex }\end{array}$} & \multirow{2}{*}{$\begin{array}{c}\text { II } \\
\text { Cotton thread } \\
20 \text { tex }\end{array}$} & \multirow{2}{*}{$\begin{array}{c}\text { III } \\
\text { Cotton thread } \\
20 \text { tex }\end{array}$} \\
\hline Thread type, linear & Front and back & & & \\
\hline $\begin{array}{l}\text { densities Front and } \\
\text { back }\end{array}$ & Back strip & $\begin{array}{c}\text { Cotton thread } \\
100 \text { tex }\end{array}$ & $\begin{array}{c}\text { Cotton thread } \\
100 \text { tex }\end{array}$ & $\begin{array}{l}\text { Cotton thread } \\
100 \text { tex }\end{array}$ \\
\hline \multicolumn{2}{|c|}{ Knitted surface density $M_{s},\left(g / m^{2}\right)$} & 405.1 & 372.2 & 367.3 \\
\hline \multicolumn{2}{|c|}{ Thickness $\mathrm{T},(\mathrm{mm})$} & 1.82 & 1.97 & 2.3 \\
\hline \multicolumn{2}{|c|}{ Dimensional density $\delta\left(\mathrm{mg} / \mathrm{cm}^{3}\right)$} & 222.6 & 188.9 & 159.7 \\
\hline \multicolumn{2}{|c|}{ Air permeability $\mathrm{B}\left(\mathrm{cm}^{3} / \mathrm{cm}^{2} \cdot \mathrm{sec}\right)$} & 17.5 & 20.2 & 20.6 \\
\hline \multirow{2}{*}{ Breaking force $\mathrm{P}(\mathrm{H})$} & By height & 249 & 256 & 214 \\
\hline & In terms of width & 1506 & 1570 & 1444 \\
\hline \multirow{2}{*}{$\begin{array}{l}\text { Stretching to break L } \\
(\%)\end{array}$} & By height & 137.75 & 145.85 & 125.12 \\
\hline & In terms of width & 65.6 & 65.7 & 68.15 \\
\hline \multirow{2}{*}{$\begin{array}{c}\text { Back deformation } \varepsilon_{o} \\
(\%)\end{array}$} & By height & 75 & 82 & 80 \\
\hline & In terms of width & 83 & 67 & 80 \\
\hline \multirow{2}{*}{$\begin{array}{c}\text { Irreversible } \\
\text { deformation } \varepsilon_{\mathrm{H}}(\%)\end{array}$} & By height & 25 & 18 & 20 \\
\hline & In terms of width & 17 & 33 & 20 \\
\hline
\end{tabular}


Based on the effect of the pattern, the elements of the texture structure of the attachment knitted fabrics create a certain structure and appearance in the fabric due to the embossing on their surfaces. The pattern in this obtained knitted fabric has a significant effect on the physical and mechanical properties of the yarn: the elasticity effect: elasticity, flexibility, fluffiness and other properties. For this purpose, the effect of the backing strip included in the base of the two-layer knitted fabric attached on the basis of the pattern effect was studied [810]. Quality indicators of knitted fabrics depend on the type of raw material used and its quality, the structure of knitted fabrics and processing methods (Table 1).

The back yarn used to change the texture structure and increase the pattern effect leads to a change in the physical and mechanical properties of the backed two-layer knitted fabric.

The surface density and thickness of the knitwear are directly related to the volume density and are the main criterion (indicator) that determines the consumption of raw materials. The change in thickness relative to the surface density is inextricably linked to the density index of the ring pitch, ring height, vertical and horizontal, and the volume density also affects the tissue structure, raw material consumption, pattern formation effect [11-12].

\section{Results and Discussion}

According to the results, the surface density of the 1st variant was observed to be the highest at $405.1 \mathrm{~g} / \mathrm{m}^{2}$, while the thickness was the lowest at $1.82 \mathrm{~mm}$. The minimum surface density is $367.3 \mathrm{~g} / \mathrm{m}^{2}$ in variant 3 , and the maximum is $2.3 \mathrm{~mm}$ in thickness.

The volume density of knitwear is one of the main among the technological indicators, it shows the amount of raw material consumption in knitwear and depends on the surface density and thickness (Fig. 1).

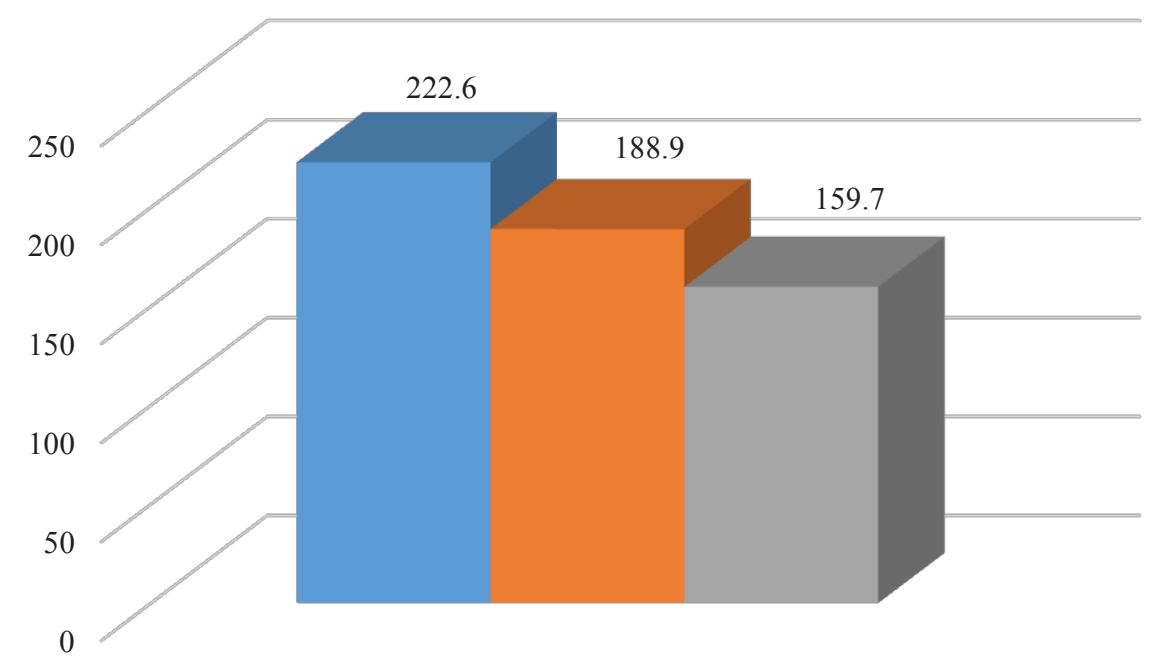

Dimensional density $\delta$ (мг/ sm 3)

Fig. 1. Histogram of volume density change of backed two-layer knitted fabric

Textile decoration is formed as a result of the use of yarns of different colors, thickness, number of weaves. The two systems of tanda yarn forming two layers of jacquard fabric, one ground and the other compressor, change their functions and the top layer goes down 
and the bottom layer tanda yarns go up, resulting in tissue decoration expansion. In the design of two-layer large-textured fabrics, great attention is paid to the appearance of the surface, which creates a variety of wrinkled, convex surface-colored ornaments [10-12].

Tissues of this type are mainly used for fabrics for outerwear for men and women. Air permeability is one of the most characteristic physical and mechanical properties that characterize the hygienic properties of the fabric, it varies with the structure of the knitted fabric, surface density, thickness. Depending on the nature of the combination of the backing thread with the underlying tissue can be divided into the following types:

- "It's a base";

- Longitudinal arch;

- Wrapping rope [12].

The air permeability of the two-layer knitted fabric with a patterned back varied from 17.5 to $20.6 \mathrm{~cm}^{3} / \mathrm{cm}^{2} * \mathrm{sec}$ (Fig. 2).

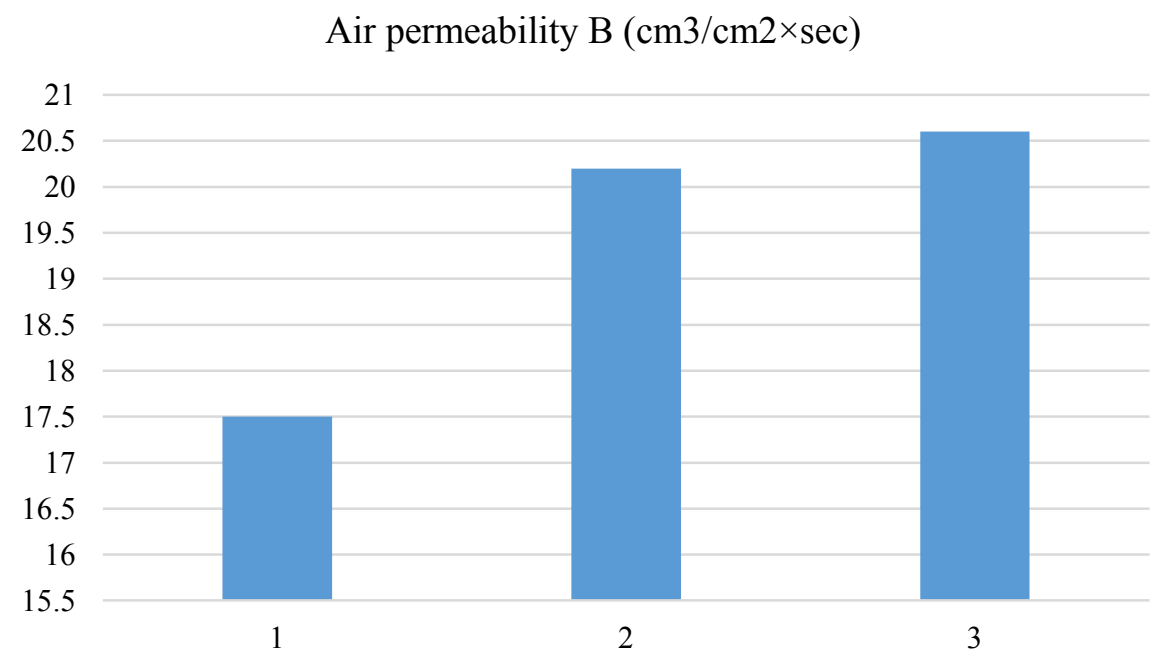

Fig. 2. Histogram of change in air permeability of two-layer knitted fabric with knitted backing

Experimental determination of patterned double-layered jacquard knitwear patterns on air permeability as a result of the introduction of back yarn in order to increase the effect of the pattern and the strength and durability of knitted fabric showed that Variant 1 knitted and backed double-layered knitted fabric had the lowest air permeability. it was 17.5 $\mathrm{cm}^{3} / \mathrm{cm}^{2} * \mathrm{sec}$, which is $32.5 \%$ less than the air permeability of the base tissue (variant 3 ).

The reason for the change in air permeability of knitted and crocheted two-layer knitted fabric in this case is that the backed yarn introduced into the jacquard two-layer knitted fabric structure by the method of knitted attachment affects the porosity of the knitted fabric, porosity shape, size and their quantity.

The tensile strength of the obtained double-layer knitted fabric with a knitted backing was determined in the standard way using a dynamometer YG-026T. All GOST and TSh applicable to knitted fabrics include normative indicators on elongation and tensile strength. Tensile force is the force required to break a specimen at a given size and speed. The breaking force is expressed in Newton units. In accordance with GOST 28554, the tensile strength was determined under the force of $850 \mathrm{~g}(8.3 \mathrm{~N})$.

The tensile strength of the tissue, i.e., the tensile strength analysis, showed that the most mature tissue in height was 2 variants, with an index of $256 \mathrm{~N}$, and $16 \%$ higher than the 3 variants (Table 1). The strength of the tissue across the width was also observed in 2 
variants, the tensile strength across the width of the tissue was $1570 \mathrm{~N}$. This is due to the use of polyester yarn as the backing thread of the patterned attachment method, due to which the texture structures change with the formation of the pattern, the loop pitch of the knitted fabric changed in variants 1 and 3 compared to variant 2 (Fig. 3).

\section{BREAKING FORCE P (H)}

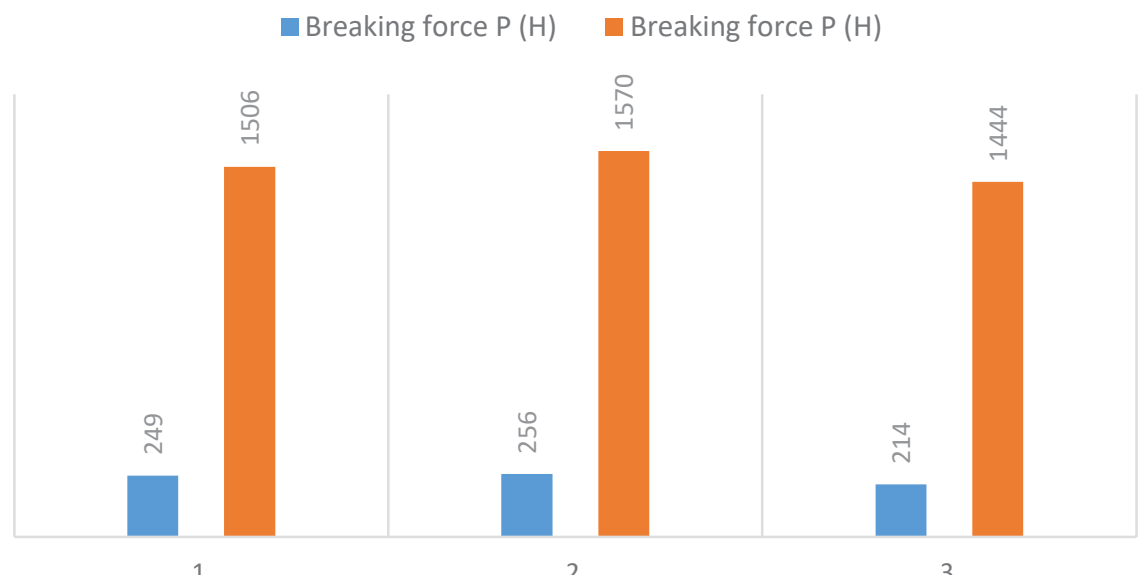

Fig. 3. Two-layer knitted fabric with a patterned back histogram of change in tensile strength index

The analysis of the tensile strength performance of two-layer knitted fabric with knitted backing shows that the presence of backing yarn in the structure of two-layer jacquard knitted fabric leads to an increase in tensile strength of all-backed two-layer knitted patterns.

\section{Stretching to break $\mathrm{L}(\%)$}

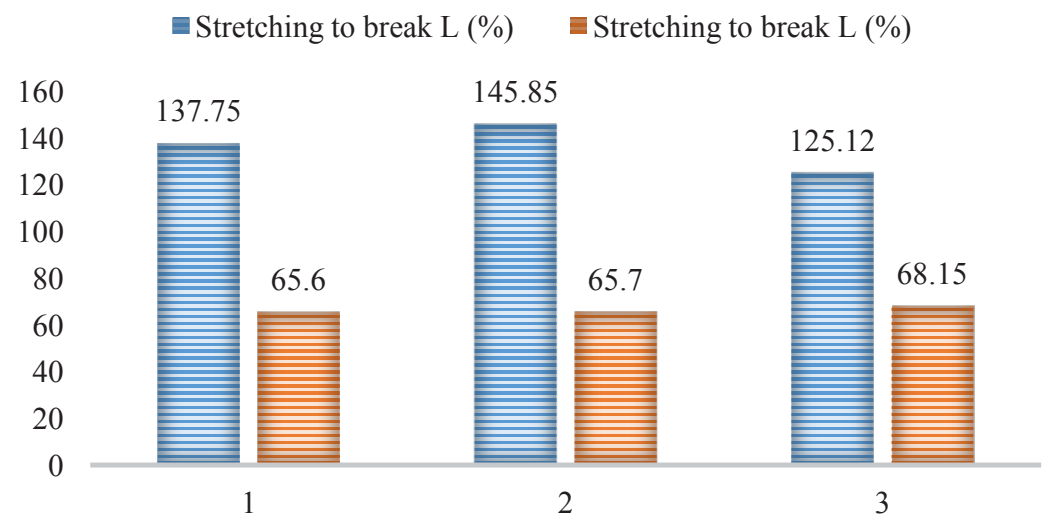

Fig. 4. Histogram of the change in the elongation of the two-layer knitted fabric with a patterned back

The resulting knitted fabric variants meet the requirements for top knitted products. In accordance with the requirements of GOST 25884 on the elongation of the two-layer knitted fabric samples with a patterned attached back, the elongation at break is significantly reduced, which in turn indicates the high shape-retaining properties of these knitted samples [11]. 
The elongation of this knit pattern ranged from $125.15 \%$ to $145.85 \%$ and the width from $65.6 \%$ to $68.15 \%$ (Fig. 4 ).

Back yarns reduce the elasticity of the base fabric, creating a less stretchy type of knitwear. The weight of this tissue is aggravated at the expense of the back strip. The thickness of the fabric also increases due to the back threads located between the base of the ring and the protruding.

A significant decrease in the elongation index across the width of the knitted fabric is due to the introduction of the backing strip into the structure of the two-layer knitted fabric and the method of knitting.

The elastic properties of knitted fabrics are determined by the rate of re-deformation. The higher the proportion of re-deformation in the fabric, the higher the shape-retaining properties of products made from it, and its elongation index is improved due to the introduction of the backing strip.

The proportion of back deformation along the length of the backed two-layer knitted fabric samples ranged from $75 \%$ to $82 \%$, and the proportion of back deformation across the width ranged from $67 \%$ to $83 \%$.

Such a proportion of back deformation indicates that the double-layered knitted fabric samples under study are rapidly returning to their original state after elongation.

The deformation of the knit varies with the elasticity of the yarn, the stiffness, and the change in the number of loops. Not only the description of the deformation, but also the state of the knitting is determined by the internal, two main forces: the elastic force of the yarn bending into the ring tends to straighten the yarn and change its shape. The result is a frictional force between the threads, which prevents the placement of the threads in the loop and interferes with the structure of the knitted fabric [7].

The elongation characteristic of the obtained knitted backed knitted fabric was determined on the model YG026A-III. The samples were prepared to a length of $30 \times 5 \mathrm{~cm}$ and were subjected to a force of $850 \mathrm{~g}(8 \mathrm{~N})$ for 30 minutes.

According to the results obtained, the proportion of irreversible deformation ranged from $18 \%$ to $25 \%$ along the length. The most durable fabric in height was observed in variant 1, but does not comply with GOST 28882 (not more than 15-20\%), which is applied to knitted outerwear. Variation in width from $17 \%$ to $20 \%$ was observed and corresponds to the normative values set in GOST and TSh (Fig. 5).

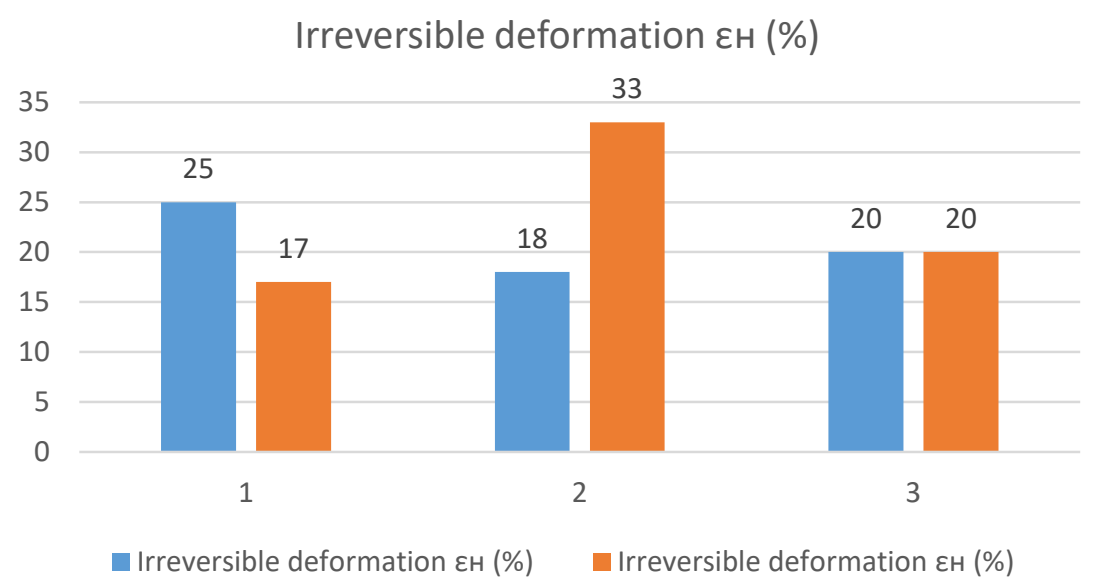

Fig. 5. Histogram of irreversible deformation change of two-layer knitted fabric with a patterned back 


\section{Conclusions}

Resource-saving technology of two-layer backed knitted fabric has been developed by inserting the back yarn into the middle layer of the knit and creating a new structure of knitted knitted fabric using highly spun cotton yarn with high hygienic properties on the other two layers. Technological parameters of two-layer backed knitted fabric, analysis of physical and mechanical properties showed that in the production of knitted products, the use of two-layer backed knitted fabrics has reduced raw material consumption. A new method of obtaining a double-layered knitted fabric with a relocation of the back yarn in the knitting fabric has been developed on a circular double-needle weaving machine.

\section{References}

1. H. R. Xanxadjayeva, Theoretical bases of pattern making, 244 ("Communicator" Press, Tashkent, 2010)

2. E. Alimbaev, Tissue structure theory, 162 ("Communicator" Press, Tashkent, 2005)

3. S. Rakhimkhojaev, D. Kodirova, Modern methods of tissue design, 142 ("Sparks of Literature" publishing house, Tashkent, 2010)

4. Sh. Shogofurov, I. Kamalova, Q. Xoliqov, U. Meliboev, Solid State Technology 63(6), 11798-11807 (2020)

5. A. Juraboev, Q. Kholiqov, Sh. Shog'ofurov, ACADEMICIA: An International Multidisciplinary Research Journal 10(4), 397-404 (2020)

6. K. Kholikov, A. Zhuraboev, SH. Shogofurov, D. Abduvaliev, The Way of Science 1(71), 11 (2020)

7. K. M. Kholikov, M. M. Mukimov, Bulletin of the Scientific and Technical Institute of the Namangan Institute of Engineering Technologies 4(1), 41-46 (2019)

8. Sh. Shogofurov, K. Kholikov, Asian Journal of Multidimensional Research 10(2), 119124 (2021)

9. Sh. Sh Shogofurov, R. S. Umarjonovna, K. I. Ibroximovna, K. K. Madaminovich, South Asian Journal of Marketing \& Management Research 11(2), 68-73 (2021)

10. T. Allamuratova, A. Djuraev, M. Mukimov, International Journal of Advanced Research in Science, Engineering and Technology 5(10), 7178-7185 (2018)

11. T. Allamuratova, M. Mukimov, International Journal of Advanced Research in Science, Engineering and Technology 5(2), 5136-5141 (2018)

12. B. Grazyna, S. Edward, Fibres and Text. East. Eur. 10(4), 45-48 (2002) 